\title{
A deaf world in Rampton Hospital*
}

\author{
Julia RoBerts, Consultant Psychiatrist, Pontefract General Infirmary, Southgate, \\ Pontefract WF8 1PL
}

Rampton Hospital is one of four Special Hospitals in England and Wales. Along with the other Special Hospitals, it usually has a small number of deaf patients. I had developed a special interest in the particular problems of psychiatrically ill deaf patients and it seemed fortuitous that I should spend a year of my senior registrar training at Rampton Hospital.

When I arrived at the hospital there were only three patients who were severely hearing impaired. All were male and had been in hospital for many years. One patient was so disturbed that it was difficult to have any meaningful communication with him. The others, despite their handicap, could make themselves reasonably understood by most of the staff who worked with them. This was especially true of one man who, in fact, had good verbal ability and lip-reading skills, and was being taught by an outside worker so that he could in turn teach some of the staff and patients the rudiments of British Sign Language (the language of the deaf which involves manual communication).

Coincidentally, shortly after I started, a further three deaf patients were admitted in quick succession. As they settled on their respective wards I gradually acquainted myself with them. It became increasingly apparent that they were all at a considerable disadvantage in terms of their immediate and long-term care and management.

Apart from myself none of the medical staff had even a rudimentary grasp of manual communication. Several nurses had attended British Sign Language ('signing') classes at a very basic level, and one had taken this further on his own initiative. The excellent Education Department at Rampton Hospital could boast of two teachers who had also started to learn how to communicate with the deaf. Thus, in a staff of ove 1,100 , there were four capable of communicating with our six deaf patients, and this at a very basic level. This was not to belittle the efforts of those nursing staff who worked with the deaf patients on a dayto-day basis. All the deaf patients could lip-read to a varying degree and there was always gesture, mime and facial expression. Four patients could write words or short sentences when all else failed. Naturally, these makeshift arrangements proved wholly unsatisfactory when misunderstandings arose and tempers escalated, often over trivial incidents.

*The views expressed in this article do not necessarily reflect those of the Department of Health.
Social work involvement is very important in a Special Hospital setting, especially with regard to informing patients of their rights under the Mental Health Act 1983. There were, however, no specialist social workers for the deaf working in the hospital and, therefore, local experts were approached. They proved extremely helpful. However, they were unable to visit regularly due to other commitments and, for the most part, staff and patients had to fall back on their own resources.

\section{An opportunity presents itself}

The patients were dispersed throughout the hospital. Some met in the Education Department but for the most part they were on their own wards and tended to become isolated from their peers because of their communication difficulties. Here then was an opportunity to bring the deaf patients together on a regular basis for peer group support. They could then 'chat' in their own language and a regular forum could be provided for questions and discussion.

It was anticipated that the deaf patients would have difficulty in grasping many concepts which would benefit from explanation. With one exception, all were profoundly deaf and obtained no benefit from hearing aids. They had never experienced verbal language. Had they been allowed to grow up using their own natural form of communication (British Sign Language) their psychological development may have been more normal. As it was, they were emotionally, psychologically and educationally deprived because their own language had been denied them during their formative years due to an emphasis on the verbal acquisition of speech. These patients only managed to pick up sign language outside school in later life from other people similarly afflicted. This meant that, for these patients in particular, they had little understanding of the reasons for their offences. They knew that they were wrong, but only because they had been told so. They lacked the moral sense which most people develop unconsciously, principally because of their total lack of verbal input.

The patients were considered to be very dangerous. Because of their communication difficulties this meant that serious problems could arise in the group. It was, therefore, decided that each patient who attended the group should be accompanied by a key 
worker. This might have proved disadvantageous by inhibiting patients from expressing their thoughts and feelings. However, there were advantages to this arrangement. It meant the establishment of a special relationship between the patient and his key worker which was heightened by the fact that they were going off the ward to a 'special' group meeting which began to acquire a higher status in the hospital. It was often helpful during the group sessions that the patient's key worker might understand a gesture or sign because he was familiar with the patient's way of communicating, whereas the rest of us would be left floundering. Possibly more important was the insight gained by the key workers into the deaf culture and background, including the manner in which deaf people reason and deal with things.

Setting up the group was administratively difficult. There were implications for staffing. Continuous problems were experienced trying to ensure that the key workers were present, especially when annual leave, sick leave and cross cover intervened. Despite this, most, particularly the ward nursing staff, were extremely enthusiastic and remained so throughout the life of the group.

\section{Beginnings}

It was with some trepidation that my co-worker (a nursing colleague) and I went into the first discussion. A poor attendance and lack of interest was anticipated but to our surprise the patients and staff were all present and eager to start. The first meeting was spent in explaining the importance to the deaf patients of meeting together and in seeking their suggestions as to how they might best be able to use the group. Even at this early stage it was obvious that as a group the deaf patients wanted to be told what to do and they found it hard to respond when asked for their opinion. Overcoming their egocentricity was a recurring difficulty. One patient would say something in passing which would be picked up by another who would then start off on a conversation of his own almost entirely unrelated to the previous topic and in which no one else could participate.

Another problem which repeatedly occurred was the patients' lack of flexibility. If someone expressed an opinion it became impossible to argue the case with him and, similarly, the other deaf patients would adopt the same attitude. However, despite these difficulties, this first group went well and helped break the ice. It was thereafter decided to meet fortnightly in a room on one of the wards with as many people as possible present.

\section{Middle}

Thereafter the group functioned well and staff remained keen to attend. The personalities of the deaf patients slowly emerged and many difficulties they shared as a group were aired. The problems of communication remained ever present and were only relieved when on two occasions we fortunately had the loan of an interpreter. The latter was very helpful in explaining what some of the deaf patients were trying to get across, and also in serving to highlight our own deficiencies and demonstrating just how much we might be missing from the conversations which the patients were having among themselves. This was not entirely a drawback because the purpose of the group was for deaf patients to come together and use the group for their own purposes. Unfortunately, one patient who was quite paranoid was noted by the interpreter to be spreading suspicion among the group. Obviously it was important that we should use this information and it was fortunate that the interpreter was present at the time, but I am sure there were other asides and little snippets of conversation which we missed. This, of course, was most unsatisfactory in view of the psychopathology displayed by some of the patients, but at the time we had no other resources to overcome this difficulty.

A recurring theme which emerged was the deaf patients' difficulty in understanding the reasons for their admission to Rampton Hospital in the first place. Was it any different from prison? Could they not go to an ordinary hospital? Could they not return home? Not infrequently when deaf people come into contact with the law, allowances are made for their deafness. The outcome may be that they do not suffer the consequences of their actions. Their errant behaviour may be repeated and may escalate and it may be several years before the individual does something sufficiently serious for people to sit up and take notice and decide that enough is enough. Our patients had histories of varying lengths involving unacceptable behaviour of varying degree. The majority had no idea that they had ever behaved in an unacceptable manner and it was, therefore, understandable that they should find difficulty in comprehending their admission to a secure hospital.

Although most of our patients had little, if any, experience of prison because of the secure nature of their hospital environment (bars on the windows and uniformed staff), it was perhaps not surprising that they should think they were in a prison. It was virtually impossible, despite repeated attempts, to persuade them that the nursing staff were primarily there to help them.

As our patients had an immature view of right and wrong, they could not appreciate why they had to spend time in a Special Hospital after committing a particularly horrific crime, especially having promised that they would not repeat it. It was almost impossible to get them to understand the seriousness of their illnesses or their crimes. The necessity for them to demonstrate a sustained period of stable 
behaviour and a change in attitude was lost on them. They felt that if they had been calm and well for a few days, this should suffice for them to be allowed home.

Patients' rights under the Mental Health Act 1983, Mental Health Review Tribunals and the Mental Health Act Commission were concepts not easily communicated to our deaf patients. This was brought home to us when we were asked to bring up the topic of Mental Health Review Tribunals by one of the social workers who was having trouble explaining it to one of the patients. The topic was introduced at the next group and, having fingerspelled it and then written it down and still received no response, it soon became clear that this topic had been completely lost on the patients. The group was, therefore, able to perform a useful function in this respect; over the next fortnight all the deaf patients applied to the Tribunal as a result of the additional explanations. It was the same story with other aspects of the Mental Health Act and detention in hospital.

Peer group support was an important element in the regular meetings. The youngest patient was helped to come out of his shell and instead of being absorbed in his own life, he became interested in what the others were saying and began to participate in the general discussion.

On one occasion another member of the group had been quite disturbed - he had been secluded and transferred to the high dependency ward. He explained what had happened and several other patients were able to talk to him about their own experiences and to empathise with him. Another patient had had repeated outbursts of difficult behaviour over many years which had become more frequent just prior to the group starting. The other members were able to encourage him to control himself sufficiently so that he could come to the next meeting and be able to tell everyone that he had not lost control. This was so successful that eventually, after a period of prolonged stability, he was able to be returned to a low dependency ward-significant progress for this particular patient.

The nursing staff in turn learnt about the patients' common background - four out of the five had been to schools where they were not allowed to communicate manually. They had been forced to sit on their hands when the teachers saw them gesticulating. All the patients thought this wrong and that as a result they had become inhibited in their development of communication. Also at this time they talked about their feelings regarding hearing people - there was a great deal of animosity; they seemed to be saying that they had been treated unfairly and they had very little respect for hearing people.

\section{End}

At the end of the series of meetings the patients were asked for their opinions about the future of the group. They all expressed a desire for it to continue and felt that it had been a useful exercise. They had enjoyed 'talking' together and thought that in the future the meetings should be less formal, more frequent and last longer. They thought it important to maintain the regular contact established by the group.

\section{The future}

This development seemed to fulfil a need which would not have been met otherwise. Initially there were no specialist services for the deaf but over the course of the year the Education Department reorganised so that the deaf patients could be taught together by those teachers who could communicate with them toa certain degree. There is now an interpreter for the deaf who visits the hospital weekly and assists all disciplines in their contact with the patients. Obviously, as there are only a small number of deaf patients, it would be impossible to justify large numbers of specially qualified professionals to help them during their stay in Rampton Hospital, but as more and more people became involved in their management and consequently became more aware of the problems, it became increasingly difficult to ignore the urgent need for a minimum number of staff to care for and communicate with these patients. Various events in the group and our growing knowledge of the patients through daily contact have combined to show that deafness is far more than just a communication barrier and has far reaching implications. These have to be taken into account in the management of deaf patients, not just in the unusual environment of a Special Hospital, but in any caring establishment where deaf people are being treated.

\section{Acknowledgement}

To the deaf patients and staff at Rampton Hospital for making the group possible and Emmet Larkin and Joan Clifton for their invaluable help. 